\title{
Analysis and Comparison of Mean Sea Level Discrepancy in Manila and Legazpi Bays using Geodetic Leveling, Gravity Field and Oceanographic Approaches
}

\author{
Rosalie B. Reyes ${ }^{1, *}$, Gerard Carpena ${ }^{2}$ and Xavier Zaragosa ${ }^{3}$ \\ ${ }^{1}$ Department of Geodetic Engineering, University of the Philippines \\ Diliman, Quezon City, Philippines \\ ${ }^{2}$ AMH Philippines Inc. \\ Quezon City, Philippines \\ 3AMH Philippines Inc. \\ Quezon City, Philippines \\ *Corresponding author's email: rbr_lally [AT] yahoo.com
}

\begin{abstract}
The determination of the mean sea level (MSL) is very important in geodetic measurements. However, the accelerating rise in sea level brought about by climate change introduces uncertainties in present observations. While the effects of accelerated sea level rise vary according to geographical location, local climatological and geophysical conditions (e.g. geodynamics or tectonic activities) may contribute significantly to its overall effect. This effect may result to elevations that are not homogeneously distributed throughout the country, meaning that benchmark height determined from two different reference MSLs will give different values.
\end{abstract}

Geodetic leveling is the classical approach in propagating heights landward but this is not applicable on lands separated by large bodies of water. This is a problem for an archipelagic country such as the Philippines. As an alternative to geodetic leveling approach, gravity field and oceanographic approaches were tested to determine the discrepancy between local MSLs. The results from these alternative approaches were compared with the result of the geodetic leveling approach that was used for validation. The MSLs used for Manila and Legazpi Bays were the averaging of 19 years tidal observations from 1990-2008 and 1989-2007 respectively.

Based on the results of this study, the MSL in Manila Bay is higher by $23.6 \mathrm{~cm}$ than the MSL in Legazpi Bay determined from geodetic leveling approach. The oceanographic approach showed a $19.5 \mathrm{~cm}$ difference between the two bays, which is $4.1 \mathrm{~cm}$ off with the with geodetic leveling approach value. Among the three gravity field models evaluated, EIGEN-6C4 gave the closest value to the geodetic leveling approach computed MSL difference. The gravity field approach computed difference between the two locations is $24.2 \mathrm{~cm}$, which differs by only $0.6 \mathrm{~cm}$ than the geodetic leveling approach value. Therefore, it can be concluded that the gravity field approach can be used as an alternative method to for inter-island height unification. However, further investigation should be conducted since only two locations were considered.

Keywords_- Geodetic leveling, Gravity field model, Mean Sea Level, Mean Sea Surface, Unification of vertical datum

\section{INTRODUCTION}

Topographic heights in the Philippines are referenced from different mean sea level (MSL) observed from tide gauges (TG). For an archipelagic country of more than 7,100 islands this could mean that heights are measured relative to the nearest TG. MSLs are not at the same level anywhere [1-5], therefore heights in its entirety are not homogeneous. This means that height of a point determined from leveling coming from two reference MSLs will give two different values. This is one of the disadvantages of local vertical datum (LVD) defined from disparate MSLs.

The International Association of Geodesy is now advocating a global vertical reference system (World Height System-WHS) that could unify regional height systems [6]. The Philippines through the initiatives of the National Mapping and Resource Information Authority (NAMRIA) is now shifting from local datum to geocentric datum. This timely activity also includes the modernization of the vertical reference system. The development of the Philippine Geoid 
Model in 2014 or PGM 2014 [7] is one of the steps towards its realization. However, its adoption would require deliberate study to relate the old vertical reference system to the new system. This would need analysis of MSL discrepancies and how much these MSLs depart from the geoid. This study aims to determine the MSL discrepancies and to analyze the different approaches in height unification that can be used for inter-island LVD unification where geodetic leveling is not possible.

In this study three methods to analyze the MSL discrepancies were used: 1) geodetic leveling approach; 2) gravity field approach; and 3) oceanographic approach [8]. Geodetic leveling approach is the classical approach [9] in determining MSL discrepancies. This requires conducting geodetic leveling from one tide gauge benchmark (TGBM) to another. However, this is only applicable on TGBMs in one land mass and never on inter-island. This approach is disadvantageous in long distances due to the propagation of errors. The gravity field approach uses a gravity field or geoid in conjunction with ellipsoidal heights measured from Global Navigation Satellite System (GNSS) observations. The oceanographic approach requires the use of ocean model such as Mean Sea Surface (MSS) or Mean Dynamic Topography (MDT) and TG observations. Ocean models are derived from satellite altimetry data from earth orbiting satellites such as TOPEX/ POSEIDON, ERS 1, Jason 1 and 2. In this approach the local MSL determined at TG was compared with the MSS ocean models. The baseline data by which comparison were made was the value derived from geodetic leveling approach.

\section{DATA USED}

\subsection{Leveling data}

The leveling data were supplied by the Geodesy Division of NAMRIA based on the first-order leveling done from TGBM MLA (tide gauge benchmark in Manila) to TGBM LGP (tide gauge benchmark in Legazpi City) in 2009 through 2011. The total length of the differential leveling was around $528 \mathrm{~km}$. TGBM MLA has a height of $1.306 \mathrm{~m}$ referenced from 2008 MSL MLA (1991-2008 MSL series). The height of TGBM LGP is $2.111 \mathrm{~m}$ based on the differential leveling referenced from TGBM MLA. TGBM LGP was also leveled from 2007 MSL LGP (1990-2007 MSL series) and the result was $1.876 \mathrm{~m}$. Figure 1 showed the leveling line between the two TGBMs.

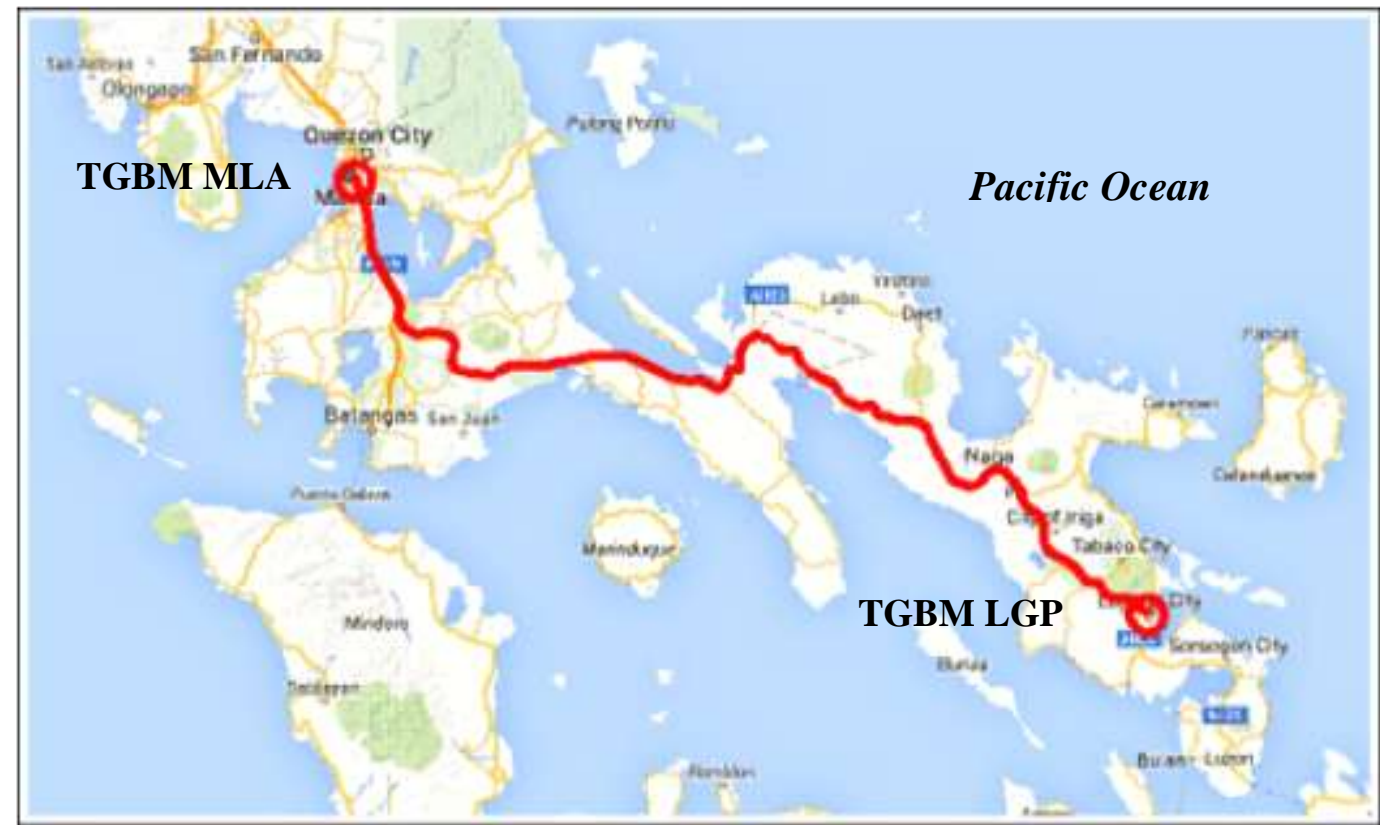

Figure 1: The study areas, leveling line and location of TGBMs

\subsection{Tide data}

The Oceanography Division of NAMRIA provided the tidal data from which the MSL were derived. Manila Bay has the longest TG data and has already undergone five (5) MSL series from its installation since the 1900's. The MSL is determined from averaging the hourly heights observed for 19 years (Metonic cycle). The present MSL was determined from 1990 to 2008 averaging of hourly sea level. Based on the tidal records Manila Bay annual MSL is exhibiting accelerated sea level rise or ASLR. According to the study by Perez et al., [10] these are caused by deposition from river 
discharges and excessive reclamation. The annual MSL trend from 1947 to 2010 referred from the local zero tide staff or OTS is shown in Figure 2. The ASLR rate is around $13 \mathrm{~mm} /$ year based on the recent data from NAMRIA.

The current MSL value in Legazpi City was based on hourly sea level observations from 1989 to 2007. The TG in Legazpi Bay has one of the second longest observations among the Primary TGs in the Philippines. Similar to Manila Bay MSL, Legazpi Bay MSL is also exhibiting an increasing trend. From 1947 to 2009 the increase in annual MSL is $0.28 \mathrm{~m}$ with a sea level rise rate of around $4 \mathrm{~mm} / \mathrm{year}$. Also shown in Figure 2 is the annual MSL trend in Legazpi Bay.

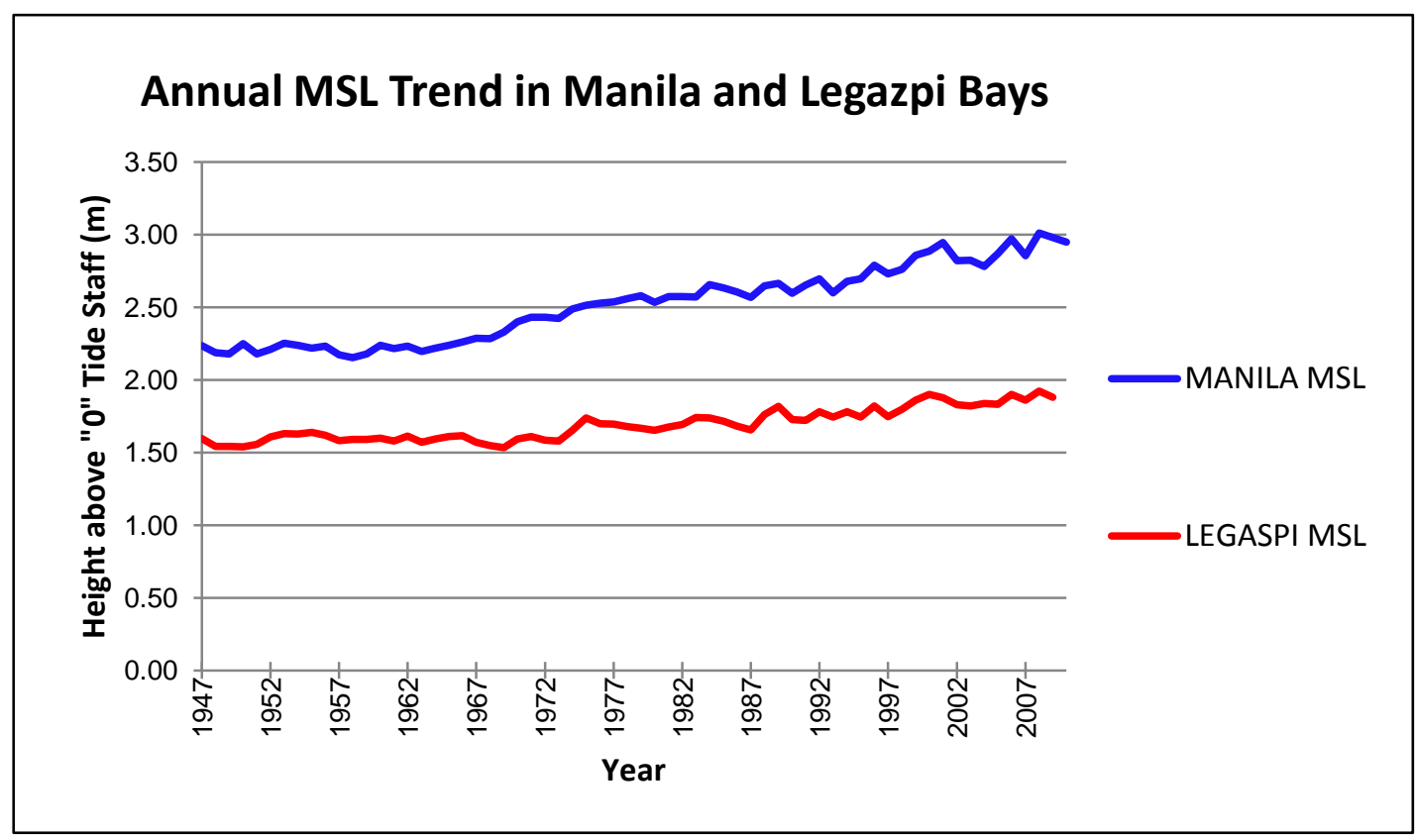

Figure 2: Annual MSL trend in Manila and Legazpi Bays

\subsection{GNSS data}

Selected BMs including the TGBMs in Manila and Legazpi were occupied with GNSS receivers. The purpose of this activity was to validate the discrepancy of the geoid height $(N)$ derived from GNSS-leveling or geometric $N\left(N_{\text {geom }}\right)$ with the geoid height extracted from the geoid models $\left(N_{\text {grav }}\right)$. The $N_{\text {geom }}$ was computed using the formula $N_{\text {geom }}=h-H$, where $h$ is the ellipsoidal height from GNSS observation and $H$ is the orthometric height derived from geodetic leveling. There were 10 BMs occupied by GNSS receivers in Legazpi City and 21 in Metro Manila. The TGBMs were also surveyed with GNSS receiver to determine the ellipsoidal heights in order to relate its level to the reference ellipsoid. The GNSS observations in Manila and Legazpi were done in 2012 and 2014 respectively.

\subsection{Gravity field models/Geoid models}

There are three (3) geoid models that were evaluated in this study to determine which surface fits the local MSL namely: 1) Philippine Geoid Model of 2014 or PGM 2014 [7]; 2) Earth Gravity Model of 2008 or EGM, 2008 [11] and European Improved Gravity model of the Earth by New techniques or EIGEN-6C4 [12]

The PGM is a regional/local geoid model developed for NAMRIA by R. Forsberg in 2014 using EGM 2008 and airborne and surface gravity measurements. The method used in its development was the Remove-Compute-Restore Method (RCR). NAMRIA is still in the process of validating the accuracy of the model. The EGM 2008 was developed by the National Geospatial-Intelligence Agency in 2008. It has a nominal resolution up to degree/order (d/o) 2190 and spatial resolution of $5^{\prime}$ or around $9 \mathrm{~km}$. The model was developed using satellite gravity, satellite altimeter and terrestrial gravity data. The EIGEN-6C4 was developed by GFZ (Deutsches GeoForschungs Zentrum) Potsdam, Germany and GRGS (Groupe De Recherche De Geodesie Spatiale) Toulouse, France in 2014 using combinations of satellite data from LAGEOS (Laser Geodynamics Satellites, ILRS 2012), GRACE (Gravity Recovery and Climate Experiment, Tapley 2004) and GOCE (Gravity field and steady-state Ocean Circulation Explorer, Drinkwater 2003) gravity data, satellite altimetry and DTU (Technological University in Denmark) global gravity anomaly data used in EGM 2008. The nominal resolution is up to $\mathrm{d} / \mathrm{o} 2190$. 


\subsection{Ocean models}

The ocean model Mean Sea Surface (MSS) was used for the oceanographic approach. The heights from this model are determined from averaging the sea level measured through satellite altimetry for several years. In the local setting this is comparable to measuring the sea level at TG stations using tide gauge instruments. The DTU10 MSS [13] is a global high resolution MSS from DTU Space. This model is based on multi-mission satellite altimetry from different satellites. The data used for its development was based on 17 years satellite altimetry measurements. The spatial resolution of the MSS model is 1' $\mathrm{x} 1$ ' or $2 \mathrm{~km} \times 2 \mathrm{~km}$.

\section{METHODOLOGY}

\subsection{Study areas}

For the preliminary investigation of MSL discrepancies, two study areas were considered: Manila (MLA) and Legazpi (LGP) Bays. Manila Bay is facing the West Philippine Sea while Legazpi Bay is on the side where the Pacific Ocean is located. The areas are located in Luzon Island and situated in the west and east extremes. The TGBM LGP is about 300 kilometer west and 159 kilometer south of TGBM MLA. TGBMs MLA and LGP are located $14^{\circ} 35^{\prime}$ N, $120^{\circ} 58^{\prime}$ E and $13^{\circ} 9^{\prime} \mathrm{N}, 123^{\circ} 45^{\prime}$ E respectively. Among the TGs in Luzon Island these two are the oldest, thus have the longest tidal observation data. In addition, the TGBMs heights were already connected by geodetic leveling. Figure 1 shows the location of the study areas.

\subsection{Geodetic leveling approach}

The usual reference datum for leveling is the MSL, which is taken as the "zero level". From this "0" level, ground heights are propagated landward through differential or geodetic leveling. Geodetic leveling is leveling to a high order of accuracy that is usually extended over large areas to furnish accurate vertical control for surveying and mapping [14]. Heights are usually marked on ground by benchmarks (BM). Tide gauge benchmark (TGBM) is a BM whose elevation has been determined with respect to mean sea level at a nearby tide gauge and used as reference for that tide gauge. To determine the discrepancy between two MSLs or LVD a leveling is run to connect the TGBMs. The discrepancy is computed from heights determined from leveling coming from two different MSLs at different locations ending on a common point. In this study the common point is the TGBM LGP. Thus the equation to determine the offset between the MSL MLA and MSL LGP is given as:

$$
D_{\text {geom }}=H_{L G P(M S L M L A)}-H_{L G P(M S L L G P)}
$$

where $H_{L G P(M S L M L A)}$ is the height of TGBM LGP determined from leveling coming from MSL MLA and $H_{L G P(M S L L G P)}$ is the height of the same BM coming from MSL LGP. This offset will be the basis for comparing the results from the gravimetric and oceanographic approaches. This is to validate if the other two approaches can be used in inter-island LVD unification where geometric approach is not applicable.

\subsection{Gravity field approach}

The availability of gravity field models or geoid models has resulted in renewed interests to define heights independent of MSL, which is unstable and time varying. The geoid is an equipotential surface derived from gravity measurements that approximates the MSL if oceanographic effects (e.g. salinity, temperature and pressure) are ignored [15]. The determination of the departure or offset of MSL from the geoid is carried out in order to establish relationship between these reference levels. The MSL offset from the geoid can be computed using the formula:

$$
O_{M L A / L G P}=h_{T G B M}-H_{T G B M}-N_{\text {geoid }}
$$

where $h_{T G B M}$ is the ellipsoidal height measured from GNSS observation at the TGBM; $H_{T G B M}$ is the height of the TGBM referenced the local MSL; and $N_{\text {geoid }}$ is the geoid height extracted from the gravity field/geoid model. The discrepancy between MSLs is:

$$
D_{\text {grav }}=O_{M L A}-O_{L G P}
$$




\subsection{Oceanographic approach}

The sea level can also be determined from satellite observations using altimetry. Since the sensor is in space this is not affected by any land displacements that coastal tide gauges are subjected to. In the open ocean the accuracy of the latest combined satellite altimetry and gravimetry missions is very high but in closed seas the quality is still questionable [16]. Although some algorithms to correct this are implemented, validation is still needed to prove the utility of the ocean model e.g. DTU10 MSS. The MSS heights are usually referred from the surface of a reference ellipsoid. In order to compare the local MSL, a GNSS observation is carried out in the TGBM to determine the ellipsoidal height. Then the local MSL height is transformed to ellipsoidal height by simply subtracting its height above MSL. The offset of the MSL from the MSS is given by the formula:

$$
O_{M L A / L G P}=h_{T G B M}-H_{T G B M}-h_{M S S}
$$

where $h_{T G B M}$ and $H_{T G B M}$ are as defined and $h_{M S S}$ is the height of the sea surface extracted from the MSS model. The discrepancy between the two MSLs using this approach is:

$$
D_{\text {ocean }}=O_{M L A}-O_{L G P}
$$

\section{RESULTS AND DISCUSSION}

\subsection{MSL local offsets}

The MSL local offsets were computed by taking the differences of the local on site measurements with the values from the MSS and geoid models. This is excepting the geodetic leveling approach whose values were directly derived measurements.

\subsubsection{Geodetic leveling approach}

The geodetic leveling approach is a straight forward analysis of the discrepancy between MSL MLA and MSL LGP. By comparing the height of TGBM LGP referred from MLA MSL with the height of the same TGBM referred from the LGP MSL, the discrepancy was determined. Table 1 shows the result of the comparison.

Table 1: Height Difference between Manila MSL and Legazpi MSL (in cm)

\begin{tabular}{|c|c|c|}
\hline Height above MSL MLA & Height above MSL LGP & Difference \\
\hline 211.1 & 187.5 & 23.6 \\
\hline
\end{tabular}

The $211.1 \mathrm{~cm}$ height above MSL was the result of the geodetic leveling done by NAMRIA from TGBM MLA to TGBM LGP. The same TGBM was leveled referred from LGP MSL and the height was determined as $187.5 \mathrm{~cm}$. A discrepancy of $23.6 \mathrm{~cm}$ was obtained, which indicate that MLA MSL is higher than LGP MSL. This value was used to validate the values derived from the other two approaches.

\subsubsection{Oceanographic approach}

For the oceanographic approach, the $h_{M S S}$ values for Manila and Legazpi were extracted from the DTU10 MSS model. The values of the $h_{M S S}$ were interpolated to the locations of the TGs since the model has a grid of one minute (1.8 km). The interpolated $h_{M S S}$ for Manila was $4406.9 \mathrm{~cm}$ while for Legazpi was $5418.2 \mathrm{~cm}$. The $h_{M S L}$ was obtained by subtracting the orthometric height $(H)$ at the TGBM from the ellipsoidal height obtain through GNSS observation $\left(h_{M S L}=h_{T G B M}-\right.$ $\left.H_{T G B M}\right)$ in order to refer the MSL to the same reference ellipsoid of the MSS model. Table 2 shows the local offsets of the two MSLs from the MSS model.

As indicated in the table the offsets are the direct difference between the two values. The results show that the heights from the MSS model are higher than the local MSL observations. The offset for MSL MLA at $24.1 \mathrm{~cm}$ is larger than MSL LGP at $4.6 \mathrm{~cm}$, which shows that MSS model fits better in Legazpi than in Manila. Further investigation should be conducted as there are studies in Manila showing that land subsidence is occurring [16, 17]. 
Table 2: Offsets of MSLs from MSS (in $\mathrm{cm}$ )

\begin{tabular}{|l|c|c|c|}
\hline & $\boldsymbol{h}_{M S L}$ & $\boldsymbol{h}_{M S S}$ & $\boldsymbol{h}_{M S L} \boldsymbol{h}_{M S S}$ \\
\hline MSL LGP & 5413.7 & 5418.2 & -4.6 \\
\hline MSL MLA & 4382.8 & 4406.9 & -24.1 \\
\hline
\end{tabular}

\subsubsection{Gravity field approach}

The gravity field model or popularly known as geoid is an approximation of the MSL. If gravity is the only force acting on the water surface, the MSL will coincide with the geoid. Due to many factors as mentioned above the MSL departs from the geoid. This departure is termed sea surface topography [2]. The offsets in the two locations are computed using the formula in Equation 2. The quantity $h_{T G B M}-H_{T G B M}$ will be referred to as $N_{\text {geom }}$ or the geoid height derived from geometric method and will be compared with the $N_{\text {geoid }}$ (e.g. $N_{E G M}$ ). Table 3 shows the computed offsets from the three geoid models considered.

Table 3: Offsets of MSLs from geoid models (in $\mathrm{cm}$ )

\begin{tabular}{|c|c|c|c|}
\hline & $N_{\text {geom }}-N_{P G M}$ & $N_{\text {geom }}-\boldsymbol{N}_{\text {EGM }}$ & $\boldsymbol{N}_{\text {geom }}-\boldsymbol{N}_{\text {EIGEN }}$ \\
\hline MSL LGP & -15.7 & 47.6 & 61.0 \\
\hline MSL MLA & -2.9 & 40.3 & 36.8 \\
\hline
\end{tabular}

The PGM 2014 has the least offsets among the geoid models. This is expected because the model was already fitted to the local MSLs. However, the negative signs indicate that the PGM 2014 level is higher than the level of the geoid derived from geometric means. Although the results from oceanographic approach showed the same sign but the values are contradicting. That is MSL LGP offset is larger than MSL MLA's offset in this approach. The offsets from EGM 2008 and EIGEN-6C4 also differ from each other. The EIGEN-6C4 fits better the MSL MLA than EGM 2008 but larger in MSL LGP. But the surfaces of both models are lower than the $N_{\text {geom }}$. If the PGM 2014 was not fitted to the local MSLs it could have exhibited the same trend with the two global models.

\subsection{Differences between local offsets}

The following Tables 4 and 5 summarize the offsets and differences from the approaches. As already given in Table 1 the difference between MSL MLA and MSL LGP using geodetic leveling approach is $23.6 \mathrm{~cm}$.

Table 4: Difference between offsets using oceanographic approach (in $\mathrm{cm}$ )

\begin{tabular}{|l|c|c|c|}
\hline & Offset & Difference & $\begin{array}{c}\text { Difference with } \\
\text { geodetic leveling }\end{array}$ \\
\hline MSL LGP & -4.6 & 19.5 & 4.1 \\
\hline MSL MLA & -24.1 & & \\
\hline
\end{tabular}

Table 5: Difference between offsets using gravity field approach (in $\mathrm{cm}$ )

\begin{tabular}{|c|c|c|c|}
\hline & Offset $\boldsymbol{N}_{\boldsymbol{P G M}}$ & Offset $\boldsymbol{N}_{\boldsymbol{E G M}}$ & Offset $\boldsymbol{N}_{\boldsymbol{E I G E N}}$ \\
\hline MSL LGP & -15.7 & 47.6 & 61.0 \\
\hline MSL MLA & -2.9 & 40.3 & 36.8 \\
\hline Difference & -12.8 & 7.3 & 24.2 \\
\hline $\begin{array}{c}\text { Difference with } \\
\text { geodetic leveling }\end{array}$ & 36.4 & 16.3 & -0.6 \\
\hline
\end{tabular}

From Table 1 the difference between the MSL LGP and MSL MLA using oceanographic approach is $19.5 \mathrm{~cm}$. It is $4.1 \mathrm{~cm}$ short of the geodetic leveling approach value. Among the three geoid models tested the EIGEN-6C4 model gives the least difference of $0.6 \mathrm{~cm}$ compared with geodetic leveling approach difference. The result showed that gravity field approach is a better alternative to oceanographic approach for inter-island height unification wherein geodetic leveling is not applicable. However, since only two locations were experimented this is not yet conclusive. 
In comparison with the approaches presented above, the gravity field approach is best recommended to unify the differing MSLs primarily because it is compatible with modern technology in height determination e.g. GNSS leveling and secondly the geoid is a time-invariant level. The Canadian leveling for example showed east (Pacific Ocean)-west (Atlantic Ocean) MSL difference of almost 1 meter. The disparate MSLs in several locations in Canada resulted in the adoption of geoid as reference level with the gravity field approach as the best choice [19]. However, in the re-evaluation of the height datum between Australia mainland and Tasmania, oceanographic models provided better estimates than geodetic-only techniques, thus also a viable alternative in local vertical datum unification [20].

\section{CONCLUSIONS AND RECOMMENDATIONS}

From the present study the following conclusions were derived:

5.1 Based on the geodetic leveling conducted from TGBM MLA to TGBM LGP, the MSL in Manila Bay was found higher than the MSL in Legazpi Bay by $23.6 \mathrm{~cm}$.

5.2 In the oceanographic approach, the comparison between the MSS and MSLs showed that the MSS model fits the MSL LGP (4.6 cm offset) than the MSL MLA $(24.2 \mathrm{~cm}$ offset). The values from the MSS model are higher than the MSLs with offset in Manila Bay larger than Legazpi Bay. The difference in offsets between the two locations was $19.5 \mathrm{~cm}$. This is $4.1 \mathrm{~cm}$ off the value from geodetic leveling approach.

5.3 Two global gravity field/geoid models; EGM 2008 and EIGEN-6C4 and one local model; PGM 2014 were considered for analysis using the gravity field approach. The PGM 2014 gave the least offsets among these models since this was already fitted the local MSLs. The local model is higher than the MSLs but the offset in Manila is smaller than Legazpi which is opposite the trend of the oceanographic approach. The two global models exhibit similar trend, which showed they are lower than the MSLs in both locations. Also, they are consistent with the geodetic leveling approach that indicates MSL MLA is higher than MSL LGP. The least deviation from the geodetic leveling approach was given by the EIGEN-6C4 model with $0.6 \mathrm{~cm}$.

5.4 An alternative to geodetic leveling approach based on the analysis of the MSL offsets from the two locations is the gravity field approach. This was provided by the EIGEN-6C4 model. Since the Philippines already have the PGM 2014, analysis should also be done on the unfitted model to analyze consistency with the geodetic leveling.

5.5 The exploration of oceanographic approach is also important as the height provided by the MSS model is reflective of the sea level because it is not affected by crustal movement since measurement is in space. Further investigation should be conducted to determine if land subsidence contributes to the apparent sea level rise in Manila Bay since the value from the MSS model is higher than the observed local MSL.

5.6 It is recommended that analysis of the MSL should be extended to all areas with TGs in the Philippines. This will help firstly in deciding whether shifting or warping the geoid is better than providing transformation parameters to relate the geoid to the local vertical datum or local MSLs and secondly to decide in selecting the best reference vertical datum to refer all heights in the country to make them homogeneous. The latter could be taken further by analyzing if the current MSL 19 year averagings are to be used as reference level since they are departing by considerable amount from the geoid based on the results. An alternative is to select a MSL series wherein it is not yet contaminated by factors contributing to sea level rise.

\section{ACKNOWLEDGEMENT}

The authors would like to thank the National Mapping and Resource Information Authority (NAMRIA) for the data provided, the Philippine LiDAR Project 1 for the GNSS receivers used in the fieldwork and the University of the Philippines Department of Geodetic Engineering (UP DGE) for supporting the fieldwork expenses. We also thank the family of Domingo Toledo for the Professorial Chair Award.

\section{REFERENCES}

[1] W. Torge, Geodesy, An Introduction. Berlin.New York, Walter de Gruyter, 1980.

[2] P. Vanicek and E. J. Krakiwsky, Geodesy: The Concepts, North Holland, 1986. 
[3] R. H. Rapp, Geometric Geodesy Part II: Department of Geodetic Science and Surveying, Ohio State University, 1993.

[4] T. H. Meyer, et al., What Does Height Really Mean? Part I: Introduction, 2004.

[5] G. Bomford, Geodesy. New York: Oxford University Press, 1980.

[6] J. Ihde, Inter-Commission Project 1.2: Vertical Reference Frames Report for the Period 2003 - 2007 " IAG, Commission Report 2007.

[7] R. Forsberg, et al., "Geoid model of the Philippines from airborne and surface gravity", 2014.

[8] J. Ihde, et al., "Realization of a global unified height system and its advances for hydrographic survey and for coastal mapping", Hydro 2010; Rostock-Warnemunde, Germany.

[9] J. H. Kwon, "Gravity and World Height system", Reference Frame in Practice, 2013; Manila, Philippines.

[10] R. Perez, et al., "Potential impacts of sea level rise on the coastal resources of Manila Bay: A preliminary vulnerability assessment", Journal of Water, Air and Soil Pollution, vol. 92, pp. 137-147, 1996.

[11] N. K. Pavlis, et al., "An Earth Gravitational Model to Degree 2160: EGM 2008", General Assembly of the European Geosciences Union, April 13-18, 2008; Vienna, Austria.

[12] C. Forste, et al., "EIGEN-6C4: The latest combined global gravity field model including GOCE data up to degree and order 2190", 5th GOCE User Workshop, 2014; Paris, France.

[13] O. B. Andersen and P. Knudsen, "The DTU10 mean sea surface and mean dynamic topography: Improvements in the Arctic and coastal zones", OSTST 2010 meeting, 2010; Lisbon, Portugal.

[14] NGS, "Geodetic Glossary," ed, 2009.

[15] P. Vanicek and N. T. Christou, "Geoid and Its Geophysical Interpretations", CRC Press. Boca Raton, Florida, USA, 1994.

[16] F. Sanso, et al., "Geoid and sea surface topography from satellite ground data in the Mediterranean region", Bulletin of Geodesy and Geomatics, pp. 155-201, 2008.

[17] K. Rodulfo and F. Siringan, "Global sea level rise is recognized, but flooding from anthropogenic land subsidence is ignored around northern Manila Bay, Philippines”, Disasters, vol. 30, no. 1, pp. 118-139, 2006.

[18] T. Deguchi, Y. Kinugasa and K. Kurita, "Monitoring of Land Deformation Using Terra SAR-X Data around Active Fault in the Metro Manila, the Philippines", FIG Working Week 2011Bridging the Gap between Cultures, 18-22 May 2011; Marrakech, Morocco.

[19] M. Véronneau and J. Huang, “The Canadian Geodetic Vertical Datum of 2013” A modernized Reference for Heights Height System Unification with GOCE, 19-20 February 2013; Noordwijk, Netherlands.

[20] M. Filmer and W. Featherstone, A Re-Evaluation of the Offset in the Australian Height Datum Between Mainland Australia and Tasmania”, Marine Geodesy, vol. 35, no.1, pp. 107-119, 2012. 